\title{
Measuring Some Indicators of the Productivity Machines Efficiency and Analysis their Impact on Productivity of the Jordanian Phosphate Company
}

\author{
Prof. Dr. Hasan Yasien Touama \\ Faculty of Economics and Administrative Sciences \\ Zarqa University, Jordan \\ hasantuama@yahoo.com \\ Dr. Hazem Khaled Shehadeh \\ Head of Business Administration Dept., \\ Faculty of Economics and Administrative Sciences \\ Zarqa University, Jordan \\ drhazemshehadeh@hotmail.com
}

\begin{abstract}
This study aimed to measure some indicators of the productivity machines efficiency as (reliability function, hazard function, and availability), and analysis their impact on productivity of the Jordanian phosphate company. To achieve the study objectives, the study depend on the machines work times and the repair times of the machines, during the period (1/11/2015 - 31/1/2016). The study findings a number of results, including:

a. There exist statistically significant (positive) relationship at the significance level $(\alpha=0.05)$, between the company productivity and the estimated values of the (reliability function $\hat{R}^{\wedge}(t)$, and availability $A(t)$ ).

$b$. There exist statistically significant (negative) relationship at the significance level $(\alpha=0.05)$, between the company productivity and the hazard function $\hat{h}(t)$.

c. There exist statistically significant impact at the significance level $(\alpha=0.05)$, for the (reliability function $R^{\wedge}(t)$ and availability $\left.A(t)\right)$ on productivity of the Jordanian phosphate company.
\end{abstract}

Keywords: Efficiency, Productivity, Reliability, Hazard Function, Availability, Jordanian Phosphate Company.

\section{INTRODUCTION}

The economists look at the productivity as the real source of the economic growth and the social wellbeing and improve the living level in any country, regardless of kind of the economic activity therein. The productivity growth rates and analysis of its elements give a closer look for the economic activity, and reveal the weaknesses and strengths in this activity. So the nations are racing for maintaining the continuity of an increasing growth rates in productivity to input the continuous improvements in the technological, managerial and human aspects, and has been able the developed nations for this path to achieve enormous industrial progress enabled it to command and control in the global economy.

The focus of the productivity improvement is to perform the work in the right way, and with better efficiently, not strenuous hard work to achieve the best results. The work with efficiently depends mainly on productive behavior of individuals, and this behavior is the result of many complex factors configure the distinctive personality of the individual, including personality factors determined by the social, heritage, and cultural environmental, including administrative and organizational factors prepares channels for efficient use of the personality factors. So it was to the community and the environment in which the individual arises impact on the type and nature of the actions of individuals and their behavior at work. The continuous improvement of the productivity requires adaptability on the correct and efficient methods to perform the work in all the activities of the community, and this means input social, educational, and behavioral changes in the community lead to the creation a new community (As-Sous, 2016: 2). 
The productive operation in any organization is based on a certain set of essential inputs (productivity machines, employees and raw materials,...). The productivity machines are the most important part thereof, it is doubtless that these machines or any part thereof are prone to breakdown or (technical failure), which leads to physical losses and waste of time beside other damages.

Thereupon, reliability evaluation of any machine must be an important base of these machines; for the reliability knowledge of each machine takes us, at the end of that, towards the proper planning of improvement and increase of (quality, productivity and efficiency of maintenance programs and productivity age), so as to produce products and services of high reliability, in harmony with the expectations and needs of the consumer which realizes the competitive advantage of the organization (Touama \& Basha, 2014: 77).

\section{Methodology}

\subsection{The Study Problem}

The study problem could be summarized as follows:

a. There exist a case of modernization and development of the essential and technological base in the Jordanian phosphate company, for plenty of productivity machines face a condition of economical extinction resulting from the international development of technology.

b. Lack of the operation scientific approach use to estimate the machines reliability and its availability in the Jordanian phosphate company.

\subsection{The Study Objectives}

The objects of this study are given as follows:

a. To identify the (MLE) method which used to estimate the reliability function, hazard function, and availability for the productivity machines in the Jordanian phosphate company.

b. To measure the relationship between the estimated values of the reliability function, hazard function, and availability with productivity of the Jordanian phosphate company.

c. To analysis the impact of the (reliability function, hazard function, and availability) on productivity of the Jordanian phosphate company.

d. To offer some importance conclusions to the decision making in the Jordanian phosphate company.

\subsection{The Study Model}

In light of the study objectives was to propose the following study model, for the purpose of measuring some indicators of the productivity machines efficiency and analysis their impact on productivity of the Jordanian Phosphate Company. As shown in the following figure No. (1):

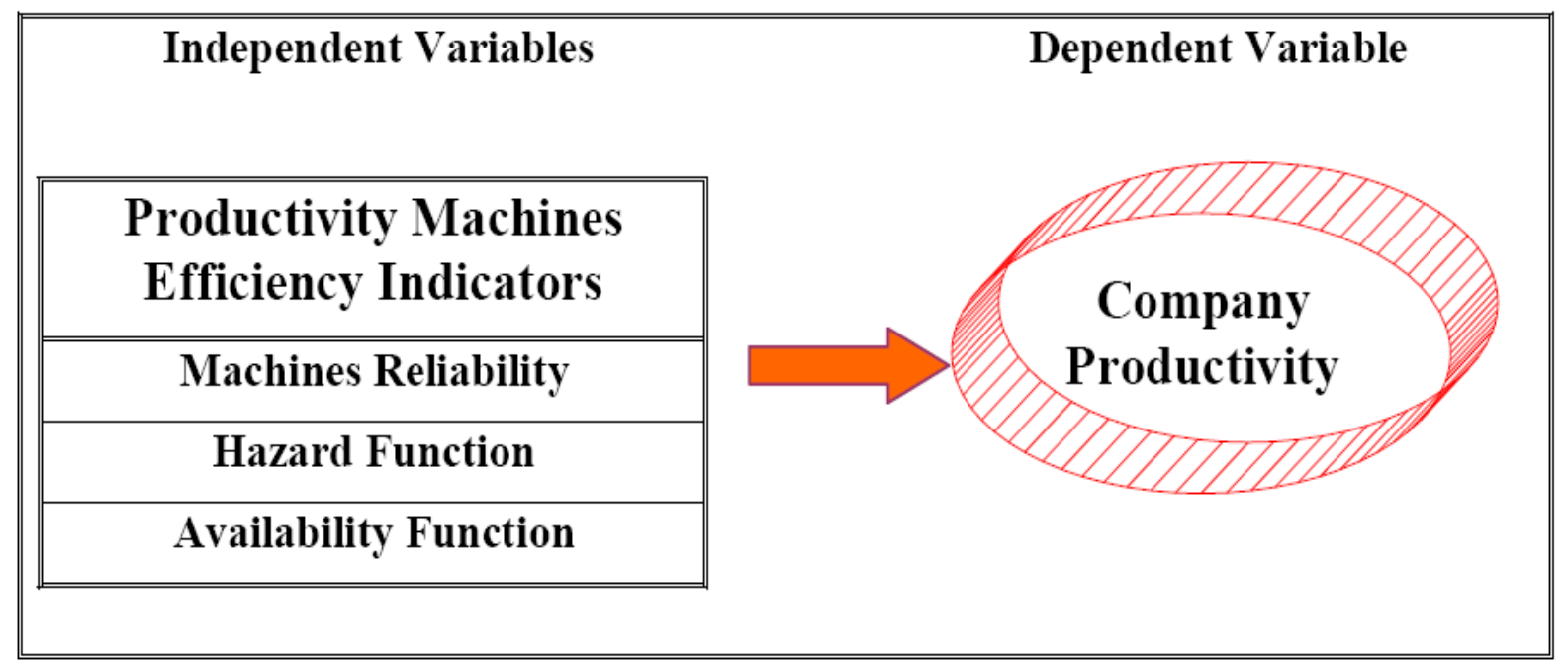

Figure1. The Study Model

Source: Prepared by the researchers. 


\subsection{The Study Hypotheses}

The study hypotheses are given in a null form $\left(\mathrm{H}_{0}\right)$ as follows:

$\mathbf{H}_{01}$ : There is no statistically significant correlation, at the significance level $(\alpha=0.05)$, between the company productivity $(\hat{Y})$ and any one of the indicators, such as (machines reliability $R^{\wedge}(t)$, hazard function $\hat{\mathrm{h}}(\mathrm{t})$, and the availability function $\mathrm{A}(\mathrm{t}))$.

$\mathbf{H}_{\mathbf{0 2}}$ : There is no statistically significant impact at the significance level $(\alpha=0.05)$, for the reliability function $\mathrm{R}^{\wedge}(\mathrm{t})$, hazard function $\hat{\mathrm{h}}(\mathrm{t})$, and the availability $\mathrm{A}(\mathrm{t})$, on productivity of the Jordanian phosphate company.

\section{Literature REVIEW}

\subsection{Productivity Concept}

The productivity concept got on a great interest by a large number of researchers and specialists, and has written about a lot of researches and studies, but they did not reach a specified and precise definition for this concept.

The productivity is defined as: the most efficient use and optimum utilization of the available resources represented by the (workforce, raw materials, and energy productivity of machinery and equipment) to produce the goods and services required (As-Sous, 2016: 4).

Hammoud (2009) is defined the productivity as: proportion or quantity or the value of products to the resources used whether it workforce, equipment, and raw materials. While Al-Khuzai (2009) indicated to the production as: indicator used to measure the size of the input required to achieve given volume of output, and that means the relationship between the input of the production elements and the output of the goods-producing.

According to the foregoing, the productivity concept had passed in successive stages of development, the productivity concept is considered old, but the interest in him still continues as the main pillar for the organization survival and achieve their objects.

\subsection{Productivity Importance}

Stands out the productivity importance through the following (As-Sous, 2016: 8):

a. Produce large quantities of units with minimum effort and minimum resources, makes the item is more able to competition their counterparts in the market.

b. Increased productivity leads to reduce the selling prices of the products, and the falling prices lead to increased the demand and increase the sales, and thereby to increase the cash inflow and increase the profits.

c. Increased productivity in the short run leads to dispose of a number of the employees, but the success of the organization and realization the profits will work in the medium and long run, on expansion of the organization and attract more of unemployed employees.

d. The productivity improvement resulting from the optimal use of limited resources with multiple uses.

e. Increased productivity leads to improved the living level and achieve the economic and social welfare of the population.

f. The productivity is considered the only source to increase the national wealth for nations.

g. Increased productivity resulting from reduced the losses in production which in turn is keeps on the limited resources of the loss.

\subsection{The Reliability Function $R(t)$}

The reliability is defined as a probability concept to be used in analyzing the random variable of positive values represented by time $(T \geq 0)$ until (time-to-failure) of any equipment, and it has a function of density probability $f(t)$ and the reliability of the equipment through out time $(t)$ is $R(t)$ which takes the following formula (Kapur, 2000):

$$
\begin{aligned}
R(t) & =P(T>t) \\
& =1-\left.t\right|^{\infty} \mathrm{f}(\mathrm{u}) d \mathrm{u}
\end{aligned}
$$




\subsection{The Hazard Function $h(t)$}

The hazard function is defined as a ratio of the failed units through a certain temporal period to that period which remained till time $(\mathrm{t})$, the hazard function $\mathrm{h}(\mathrm{t})$ takes the following formula.

$h(t)=f(t) / R(t)$

Whereas:

$f(t)$ : The probability density function of the exponential distribution.

$\mathrm{R}(\mathrm{t})$ : Reliability of the productivity machines.

\subsection{The Probability Density Function of the Machine Work Times}

The probability density function $\mathrm{f}(\mathrm{t})$ of the machines work times till that occurrence of failure is distributed as exponential distribution and takes the following formula (Abed-Ali \& et al., 2009).

$\mathrm{f}(\mathrm{t})=(1 / \theta) \mathrm{e}^{-\mathrm{t} / \theta} \quad, \mathrm{t}>0$

Whereas:

$\theta$ : Mean Time Between Failures (MTBF).

\subsection{Maximum Likelihood Estimation (MLE) Method}

This section used the (MLE) method to estimate the parameter $(\theta)$, the reliability function $R(t)$ and the hazard function $\mathrm{h}(\mathrm{t})$ of the exponential distribution, as follows (Tuama \& Basha, 2014):

\subsubsection{Estimation the Parameter of the Exponential Distribution}

We can get a formula for the exponential distribution parameter $(\theta)$ estimator, depend upon the probability density function $f(t)$ as in the relation (1) by using the (MLE) method. Thereupon the estimator of maximum likelihood of the parameter $(\theta)$ is given as follows (Singh \& et al., 2005):

$\theta^{\wedge}=\Sigma \mathrm{t}_{\mathrm{i}} / \mathrm{n}$

$=\mathrm{MTBF}$

\subsubsection{Estimation the Reliability Function $R(t)$}

The maximum likelihood estimation of the reliability function $\mathrm{R}(\mathrm{t})$ of the machine work times which is distributed as exponential distribution, takes the following formula (Nasser \& Eissa, 2005):

$R^{\wedge}(t)=e^{-t / \theta^{\wedge}} \quad, t>0$

The above estimator $\mathrm{R}^{\wedge}(\mathrm{t})$ of the reliability function is considered to be a biased estimator, and by (Lehmann \& Sheffe) theorem, we can get the unbiased estimator of the reliability function $\mathrm{R}^{\wedge}(\mathrm{t})$ as follows (Mood, Graybill \& Boes, 2004):

$\mathrm{R}^{\wedge}(\mathrm{t})=\left[1-\left(1 / \Sigma \mathrm{t}_{\mathrm{i}}\right)\right]^{\wedge(\mathrm{n}-1)} \quad, \mathrm{t}>0$

The above estimator $\mathrm{R}^{\wedge}(\mathrm{t})$ has a (MVUE) of the reliability function $\mathrm{R}(\mathrm{t})$.

\subsubsection{Estimation the Hazard Function h(t)}

The hazard function $\mathrm{h}(\mathrm{t})$ of the exponential distribution, was considered a constant value and takes the following formula:

$\mathrm{h}(\mathrm{t})=1 / \theta$

Thereupon, the maximum likelihood estimator of the function $\mathrm{h}(\mathrm{t})$ is written as follows:

$$
\begin{aligned}
\mathrm{h}^{\wedge}(\mathrm{t}) & =1 / \theta^{\wedge} \\
& =\mathrm{n} / \Sigma \mathrm{t}_{\mathrm{i}}
\end{aligned}
$$

The estimator $\mathrm{h}^{\wedge}(\mathrm{t})$ in relation (5) is considered a biased estimator, whereas the unbiased estimator of the hazard function is written as follows:

$\mathrm{h}^{\wedge}(\mathrm{t})=(\mathrm{n}-1) / \Sigma \mathrm{t}_{\mathrm{i}}$

The above estimator $\mathrm{h}^{\wedge}(\mathrm{t})$ has a (MVUE) of the hazard function $\mathrm{h}(\mathrm{t})$. 
Measuring Some Indicators of the Productivity Machines Efficiency and Analysis their Impact on Productivity of the Jordanian Phosphate Company

3.6.4. Estimation the Availability Function A(t)

The Availability defined as: efficiency of the device under the interrelated factors of Reliability and Maintainability, in completion of the required function within the terms of the specific use and during a certain time period. Be for any device good Availability if it (Monchy, 1996: 181):

a. The failure rate least that can (minimum).

b. The possibility of re-operational the device in least possible time.

Based on the foregoing, it can improve the device productivity through:

c. Increase the device reliability, in the sense increase (MTBF).

d. Reduce the repair times to a minimum, in the sense reduce (MTTR).

We can calculate the availability function $\mathrm{A}(\mathrm{t})$ for each machine depend upon the mean time between failure $\left(\theta^{\wedge}\right)$ and the Mean Time To Repair (MTTR), and by using the following formula:

$\mathrm{A}(\mathrm{t})=\theta^{\wedge} /\left(\theta^{\wedge}+\mathrm{MTTR}\right)$

Whereas:

MTTR: Mean Time To Repair.

\section{RESULTS AND DISCUSSION}

\subsection{A Glimpse of Jordanian Phosphate Company}

The Jordanian Phosphate Company was founded in 1949, where it was converted into a public company in 1953, and the company's objectives is exploration about phosphate and fertilizer industry, and contribute to the establishment of related industries. The company headquarters is located in Amman City, the company operates to extract the phosphate mainly from mines of Al-Ehasa, white and Al-Eshidiya (south of the kingdom), also the company possesses an industrial complex in Aqaba city to produce a chemical fertilizers. The company produces more than (7) million tons of phosphate rock annually, making it (sixth) country in terms of production in the world and (second) largest country in terms of export.

The year 2006 considered an important turning point in the history of the Jordanian Phosphate mines company where it was privatizing the company consistent with government's strategy at the time and intended to privatize public companies to accrue benefit on the companies performance and the national economy, also the recent years have seen a point transformation in the a starting all financial, marketing and administrative areas, for the purpose of meeting the challenge of global competition, and increasing the investments in manufacturing industries projects that make up future of the phosphate industry.

\subsection{Collection of Data}

The study data depends upon the (work and repair) times of the productivity machines and the productivity (1000 Ton) of the Jordanian phosphate company during the period (1/11/201531/1/2016). The company have many machines, and we selection thee types of them [Excavator type Pesarios, Mired Type Drake Line \& Rapier, and Crane type Greene].

Thereafter, the actual times for the machines work to be studied was registered, till the damage breakdown occurrence, where the machine damage should be repaired and return for work. Table (1) shows the study data:

Table1. The Study Data

\begin{tabular}{|l|l|l|l|l|}
\hline Years & $\begin{array}{l}\text { Company } \\
\text { Productivity (1) }\end{array}$ & $\begin{array}{l}\text { Reliability Function } \\
(\mathbf{2})\end{array}$ & $\begin{array}{l}\text { Hazard Function } \\
(\mathbf{3})\end{array}$ & $\begin{array}{l}\text { Availability } \\
\text { Function (4) }\end{array}$ \\
\hline 2010 & 6529 & 0.874 & 0.126 & 0.813 \\
\hline 2011 & 7594 & 0.926 & 0.074 & 0.898 \\
\hline 2012 & 6383 & 0.876 & 0.124 & 0.809 \\
\hline 2013 & 5399 & 0.851 & 0149 & 0.799 \\
\hline 2014 & 7144 & 0.903 & 0.097 & 0.875 \\
\hline 2015 & 6611 & 0.884 & 0.116 & 0.828 \\
\hline
\end{tabular}


(1) The Company Productivity have been extracted from the annual reports of the Jordanian phosphate company.

(2) The Reliability Function calculated by the relation No. (4).

(3) The Hazard Function calculated by the relation No. (6).

(4) The Availability Function calculated by the relation No. (7).

\subsection{Results of the Hypotheses Testing}

Before testing the study hypotheses, some tests to be applied on study data, should be validated as follows:

\section{a. One-Sample t-Test}

This test was used to validate the homogeneity of the study data. Table (2) shows the results of the test:

Table2. Results of One-Sample t-Test

\begin{tabular}{|l|l|l|l|l|}
\hline No. & Study Variables & t-values & df. & Sig. (P-value) \\
\hline 1 & Productivity & 21.722 & 5 & 0.000 \\
\hline 2 & Machines Reliability & 83.671 & 5 & 0.000 \\
\hline 3 & Hazard Function & 10.801 & 5 & 0.000 \\
\hline 4 & Availability Function & 51.096 & 5 & 0.000 \\
\hline
\end{tabular}

[The critical value of $(t)$ with $(d f .=5)$ and $(\alpha=0.05)=2.015$ ]

According to the table (2), the results showed that the study data was characterized by high homogeneity. This could be proved by $(\mathrm{t})$ values of $(21.722,83.671,10.801,51.096)$ of (company productivity, machines reliability, hazard function, and availability function) respectively. In which all these values are more than the critical value of $(t)$.

\section{b. Shapiro-Wilk Test}

This test was used to check whether the study data distributed Normal Distribution or not. Table (3) shows the results of testing the normal distribution property using (Shapiro-Wilk) test, as follows:

Table3. Results of (Shapiro-Wilk) Test

\begin{tabular}{|l|l|l|l|l|}
\hline No. & Study Variables & N & Shapiro-Wilk & Sig. (P-value) \\
\hline 1 & Productivity & 6 & 0.964 & 0.817 \\
\hline 2 & Machines Reliability & 6 & 0.971 & 0.874 \\
\hline 3 & Hazard Function & 6 & 0.971 & 0.874 \\
\hline 4 & Availability Function & 6 & 0.856 & 0.217 \\
\hline
\end{tabular}

According to the table (3), the results showed that all the statistical significance values (P-value) were more than the significance level $(\alpha=0.05)$. In light of the previous results, the variables data were distributed Normal Distribution).

After assuring that there was no Multicollinearity between independent variables, and the variables data were distributed normal distribution, making it ready for having all analytical tests.

\subsubsection{Test the $1^{\text {st }}$ hypothesis}

$\mathbf{H}_{01}$ : There is no statistically significant correlation, at the significance level $(\alpha=0.05)$ between the company productivity $(\hat{Y})$ and any one of the indicators, such as (machines reliability $\mathrm{R}^{\wedge}(\mathrm{t})$, hazard function $\hat{\mathrm{h}}(\mathrm{t})$, and the availability function $\left.\mathrm{A}(\mathrm{t})\right)$.

In order to test the validity of the $1^{\text {st }}$ hypothesis, the correlation coefficient (Pearson) has been used, as shown in table (4) below:

Table4. Pearson Correlation Coefficients between the variables

\begin{tabular}{|l|l|l|l|}
\hline The Variables & Machines Reliability & Hazard Function & Availability Function \\
\hline Productivity & $0.973^{* *}$ & $-0.973^{* *}$ & $0.901^{* *}$ \\
\hline Sig. (P-value) & 0.001 & 0.001 & 0.014 \\
\hline
\end{tabular}

** Correlation is significant at the 0.01 level (2-tailed). 
Table (4) showed the following results:

a. There exist statistically significant relationship, a positive correlation, at the significance level $(\alpha=$ $0.05)$, between the company productivity and machines reliability. This could be proved by the statistical significance value of the correlation coefficient (P-value) of (0.001) which was less than the significance level $(\alpha=0.05)$.

b. There exist statistically significant relationship, a negative correlation, at the significance level ( $\alpha$ $=0.05$ ), between the company productivity and hazard function. This could be proved by the statistical significance value of the correlation coefficient (P-value) of (0.001) which was less than the significance level $(\alpha=0.05)$.

c. Also, there exist statistically significant relationship, a positive correlation, at the significance level $(\alpha=0.05)$, between the company productivity and availability function. This could be proved by the statistical significance of the correlation coefficient value (P-value) of $(0.014)$ which was less than the significance level $(\alpha=0.05)$.

\subsubsection{Test the $2^{\text {nd }}$ hypothesis}

$\mathbf{H}_{02}$ : There is no statistically significant impact at the significance level $(\alpha=0.05)$, for the reliability function $\mathrm{R}^{\wedge}(\mathrm{t})$, hazard function $\hat{\mathrm{h}}(\mathrm{t})$, and the availability $\mathrm{A}(\mathrm{t})$, on productivity of the Jordanian phosphate company.

In order to test the $2^{\text {nd }}$ hypothesis validity was used the stepwise multiple linear regression analysis. As shown in table (5) and (6) below:

Table5. Summary of Stepwise Multiple Linear Regression Model

\begin{tabular}{|l|l|l|l|l|}
\hline $\mathbf{R}$ & $\mathbf{R}^{2}$ & $\mathbf{F}_{\text {Ratio }}$ & Sig. (P-value) & df. \\
\hline 0.901 & 0.812 & 17.101 & 0.004 & $(2,3)$ \\
\hline
\end{tabular}

[Tabulated $(F)$ with $d f .(2,3)$ at the significance level $(\alpha=0.05)]=9.55$

The results in table (5) show that:

a. Validity of multiple linear regression is proven, this is supported by the calculated value $(\mathrm{F})$ (17.101) which is greater than the critical value of $(F)(9.55)$, and that the significance value (Pvalue) (0.004) is less than the significance level $(\alpha=0.05)$.

b. The value of the $\left(\mathrm{R}^{2}\right)$ of $(0.812)$, refers to the indicators of the productivity machines efficiency which are (reliability, and availability), interprets $(81.2 \%)$ of the changes that happen in the productivity of the Jordanian phosphate company, while the remaining percentage $(18.8 \%)$ is attributable to another variables that have not been entered into the multiple linear regression model.

Table6. Results of the Stepwise Multiple Linear Regression Analysis

\begin{tabular}{|l|l|l|l|l|}
\hline Model & Coefficients $(\boldsymbol{\beta})$ & t-test & P-value & Beta \\
\hline Constant $\left(\beta_{0}\right)$ & -32103.145 & -6.231 & 0.003 & - \\
\hline Reliability & 27983.836 & 8.499 & 0.001 & 0.342 \\
\hline Availability & 16723.602 & 4.135 & 0.004 & 0.238 \\
\hline
\end{tabular}

The results in the table (6), explained that:

a. The significant of regression coefficients $(\beta)$ for two indicators of the (productivity machines efficiency) which are (reliability, and availability) were proven, therefore, there exist statistically significance impact at the significance level $(\alpha=0.05)$ for the above indicators on productivity of the Jordanian phosphate company. Depend on the statistical significant values (P-values) $(0.001$, and 0.004) respectively, and all the values are less than the significant level $(\alpha=0.05)$, this means that the null hypothesis $\left(\mathrm{H}_{02}\right)$ is rejected, based on the above results.

While, the indicator (hazard function) is not proven the significance, because has no impact on company productivity. This could be proved by its statistical significance value of $(0.842)$, which is more than the significance level $(\alpha=0.05)$. 


\section{Dr. Hasan Yasien Touama \& Dr. Hazem Khaled Shehadeh}

b. The standardized coefficients values (Beta) of $(0.342,0.238)$ rof the (machines reliability, and availability function) respectively, indicated that if the (machines reliability, and availability) increased by one unit of standard deviation, the company productivity would increase by $(34.2 \%$, $23.8 \%$ ) respectively.

According to the results of Multiple Linear Regression analysis, the predictive model was explained in the following form:

$\hat{\mathbf{Y}}_{\mathrm{i}}=-\mathbf{3 2 1 0 3 . 1 4 5}+\mathbf{2 7 9 8 3 . 8 3 6} \mathbf{R}^{\wedge}(\mathrm{t})+\mathbf{1 6 7 2 3 . 6 0 2} \mathrm{A}(\mathrm{t})$

Whereas:

$\hat{\mathbf{Y}}_{\mathrm{i}}$ : Company Productivity, $\mathrm{R}^{\wedge}(\mathrm{t})$ : Machines Reliability, $\mathrm{A}(\mathrm{t})$ : Availability function.

\section{Conclusions}

The study reached to a number of conclusions, among them the following:

a. There exist statistically significant a positive correlation, at the significance level $(\alpha=0.05)$, between the company productivity and machines reliability.

b. There exist statistically significant a negative correlation, at the significance level $(\alpha=0.05)$, between the company productivity and hazard function.

c. There exist statistically significant a positive correlation, at the significance level $(\alpha=0.05)$, between the company productivity and availability function.

d. There exist statistically significance impact at the significance level $(\alpha=0.05)$ for the indicators (reliability, and availability) on productivity of the Jordanian phosphate company.

e. There is no statistically significance impact at the significance level $(\alpha=0.05)$ for the indicator (hazard function).

f. The results indicated that the indicator (machines reliability) is the most influential on the productivity of the Jordanian phosphate company.

\section{REFERENCES}

[1] Al-Khuzai, M., (2009), Role of Human Resources Management in Raising the Productive Efficiency, University of Damascus, Syria.

[2] Abed-Ali, S.S., Fandi, S.J., and Mutlaq, S.A., (2009), Reliability Measurement for Rotary Kiln Cement Kubaysa Factory, Journal of Engineering and Technology, 27(11): 367-369.

[3] As-Sous, S.Z., (2016), Programs of the productivity improvement, Qalqilia, Palestine, pp. 2-8.

[4] Bhote K.A., (2004), World Class Reliability using MEOST to Make it Happens, Amacom.

[5] Eddy O.N., (2007), Applied Statistics in Designing Special Organic Mixtures, Applied Sciences, 9: 78-85.

[6] Gbogboade A. and Charlotte E.R., (2003), Evaluating the Reliability and Validity of Three Tools to Assess the Quality of Health on the Internet, Patient Education and Counseling, 50(2): 151155.

[7] Ghitany M.E., (2006), Reliability Properties of Extended Linear Failure Rate Distributions, Probability in the Engineering and Information Sciences, 21(2): 441-450.

[8] Hammoud, K., (2009), Total Quality Management, $4^{\text {th }}$ Edition, Dar Al-Massira for Publishing and Distribution, Amman, Jordan.

[9] Janice M., Michael B., Maria M., Karin O. and Jude S., (2002), Verification Strategies for Establishing Reliability and Validity in Qualitative Research, International Journal of Qualitative Methods, 1(2).

[10] John A., (2005), Earliest Uses of Symbols in Probability and Statistics, Electronic Document, Retrieved March 20.

[11] Kapur, K.C., (2000), Reliability and Maintainability, Handbook, CRC.

[12] Lawless J.F., (2003), Statistical Models and Methods for Life-time Data, John Wiley and Sons, New York. 
[13] Lai C.D., Xie M. and Murthy D.N., (2001), Bathtub Shaped Failure Rate Distributions, Handbook in Reliability, Balakrishnan N. and Rao, C.R. Eds., 20: 69-104.

[14] Lin C.T., Wu, S.J. and Balakrishnan, N., (2006), Monte Carlo Methods for Bayesian Inference on the Linear Hazard Rate Distribution, Communications in Statistics, Theory and Methods, 35: 575-590.

[15] Monchy F., (1996), La fonction maintenance-formation à la gestion de la maintenance industrielle, MASSON, $2^{\text {nd }}$ Edition, Paris, p. 181.

[16] Mood A.M., Graybill F.A. and Boes D.C., (2004), Introduction to Theory of Statistics, McGrawHill International Book Company, London.

[17] Nasser M., and Eissa, F.H., (2005), Bayesian Estimation for the Exponentitated Weibull Model, Communications in Statistics-Theory and Methods, 33(10): 2343-2362.

[18] Nelson W., (2004), Accelerated Testing, Statistical models, Test Plans and Data Analysis, John Wiley.

[19] Singh, Gupta, P.K., and Upadhyay, S.K., (2005), Estimation of Parameters for ExponentitatedWeibull Family under Type-2 Censoring Scheme, Computational Statistics and Data analysis, 48(3): 509-523.

[20] Touama H.Y. \& Basha M.H., (2014), Estimation the Reliability of the Productivity Machines and it's Availability for the Exponential Distribution, European Journal of Business and Management, 6(22): 77-83.

\section{ACKNOWLEDGMENT}

This research is funded by the Deanship of Research in Zarqa University/ Jordan

\section{AUTHORS' BIOGRAPHY}

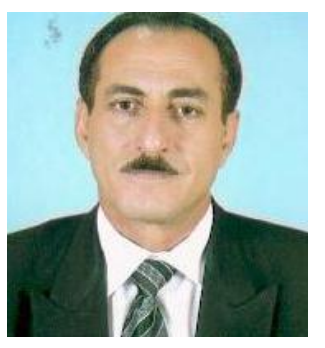

Hasan Yasien Touama, Professor of Mathematical Statistics and Quantitative Methods at Faculty of Economics and Administrative Sciences of Zarqa University in Jordan, he teaches and achieves the researches in Statistics, Quantitative Methods (Operations Researches \& Production Management), and Econometrics. He took his BA in Statistical Sciences at (1978), Master Degree in Designing \& Analyzing Experiments at (1981), and his Ph.D. in Applied Statistics and Quantitative Methods (Major) at (1995) from Baghdad University. He is the author of (16) sixteen book and over (57) fifty seven article, and study about the following subjects and fields: Applied Statistics, Bio-statistics, Experimental Design, Econometrics, Computerized Information Systems, Total Quality Management and Quantitative Methods (Operations Researches \& Production Management).

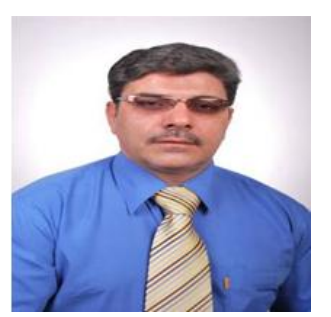

Hazem Khaled Shehadeh, Assistance Professor of Business Administration at Faculty of Economics and Administrative Sciences of Zarqa University in Jordan, he teaches and achieves the researches in Business Administration, Quantitative Methods (Operations Researches \& Production Management),. He took his BA in electrical engineering at (1990), Master Degree in Management Engineering (1993), and his Ph.D. in Business Administration (1997) from Philippines. He is the author of (2) books and seven article, and study about the following subjects and fields: Computerized Information Systems, Total Quality Management, Human Resources Management, Leadership, Marketing Management and Quantitative Methods (Operations Researches \& Production Management). 